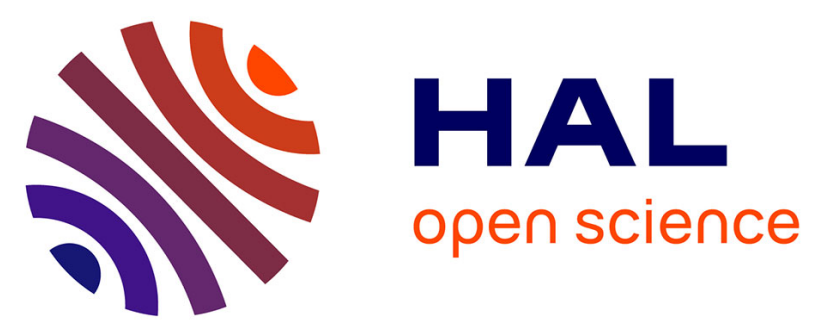

\title{
Thermoelectric Magnetohydrodynamic Flows and Their Induced Change of Solid-Liquid Interface Shape in Static Magnetic Field-Assisted Directional Solidification
}

Jiang Wang, Yves Fautrelle, Henri Nguyen-Thi, Guillaume Reinhart, Hanlin Li, Xi Li, Yunbo Zhong, Zhongming Ren

\section{To cite this version:}

Jiang Wang, Yves Fautrelle, Henri Nguyen-Thi, Guillaume Reinhart, Hanlin Li, et al.. Thermoelectric Magnetohydrodynamic Flows and Their Induced Change of Solid-Liquid Interface Shape in Static Magnetic Field-Assisted Directional Solidification. Metallurgical and Materials Transactions A, 2016, 47 (3), pp.1169-1179. 10.1007/s11661-015-3277-6 . hal-01383552

\section{HAL Id: hal-01383552 https://hal.science/hal-01383552}

Submitted on 17 May 2020

HAL is a multi-disciplinary open access archive for the deposit and dissemination of scientific research documents, whether they are published or not. The documents may come from teaching and research institutions in France or abroad, or from public or private research centers.
L'archive ouverte pluridisciplinaire HAL, est destinée au dépôt et à la diffusion de documents scientifiques de niveau recherche, publiés ou non, émanant des établissements d'enseignement et de recherche français ou étrangers, des laboratoires publics ou privés. 


\title{
Thermoelectric Magnetohydrodynamic Flows and Their Induced Change of Solid-Liquid Interface Shape in Static Magnetic Field-Assisted Directional Solidification
}

\author{
JIANG WANG, YVES FAUTRELLE, HENRI NGUYEN-THI, \\ GUILLAUME REINHART, HANLIN LIAO, XI LI, YUNBO ZHONG, \\ and ZHONGMING REN
}

Applying static magnetic field can produce flows (thermoelectric magnetohydrodynamic flows, TEMHDF) in the melt by interacting with the thermoelectric currents (TEC) during solidification of metals. A physical model was proposed to interpret how these TEC appear at the solid-liquid interface and verified by a corresponding simulation. The influences of TEMHDF on solidification were investigated through both ex-situ experiments and $n$ situ observations by means of synchrotron X-ray radiography. The 3D numerical simulations of TEMHDF were performed for these two cases, respectively, and suggested that both the change of interface shape with different transverse static magnetic fields demonstrated by the ex-situ experiments and the real time observed interface shape varying under a $0.08 \mathrm{~T}$ transverse static magnetic field could attribute to the TEMHDF advanced solid-liquid interface in the static magnetic field-assisted directional solidification. The TEMHDF produced by an axial static magnetic field were also computed along with the interface change predicted based on which is good in line with the published experimental results. This study of TEMHDF and their impacts on the solid-liquid interface shape provides a method to tailor the structure during directional solidification using static magnetic field.

\section{INTRODUCTION}

USE of the magnetic field to stir the liquid metal during its solidification and then optimize the solid structure had been tried in 1917. Motivated by a boom demand on the high-quality steels after the First World War, a European steel making company carried out this first attempt of applying magnetic field to the metallurgical process. ${ }^{[1]}$ After near a century development, several common views have been achieved on the effects of applying magnetic fields to solidification such as shifting the liquid-to-solid phase transformation

JIANG WANG, Associate Professor, is with the Shanghai University \& State Key Laboratory of Advanced Special Steel, 149 Yanchang Road, Shanghai 200072, P.R. China, and also with the IRTES-LERMPS, Université de Technologie de Belfort-Montbéliard, 90010 Sévenans, France. Contact e-mail: wangjiang417@163.com YVES FAUTRELLE, Professor, is with the SIMAP/EPM, Grenoble Institute of Technology, 1130 rue de la Piscine, 38402 St-Martin d'Heres Cedex, France. HENRI NGUYEN-THI, Professor, and GUILLAUME REINHART, Research Fellow, are with Aix Marseille University \& CNRS-IM2NP, Campus Saint-Jerome, Case 142, 13397 Marseille Cedex 20, France. HANLIN LIAO, Professor, is with the IRTES-LERMPS, Université de Technologie de Belfort-Montbéliard. XI LI, YUNBO ZHONG, and ZHONGMING REN, Professors, are with the Shanghai University \& State Key Laboratory of Advanced Special Steel. temperature ${ }^{[2,3]}$ aligning the crystal/grain orientation, ${ }^{[4,5]}$ redistributing the solutes, primary phases or inclusions, ${ }^{[6,7]}$ and damping flows in the melt. ${ }^{[8,9]}$ Yet, the comprehensive understanding is far from achieved due to the complex magnetohydrodynamic phenomena involved in the magnetic field-assisted solidification. For example, a conclusion has been accepted for long time that both dynamic (rotating, traveling, moving or pulsed) and static magnetic fields can damp flows in the melt but only the former can produce flows. ${ }^{[10]}$ For instance, Chedzey and Flemings et al. obtained the growth-striae and solute banding free crystals by applying a static magnetic field to the crystal growth process in $1966{ }^{[11,12]}$ But this was challenged in 1981, a former Soviet Union scientist Mikelson and Karkli ${ }^{[13]}$ pointed out that the static magnetic field can also produce flows during crystal growth by interacting with the thermoelectric currents (TEC) at solid-liquid interface. Ten years later, Alboussiere and Moreau et al. ${ }^{[14]}$ observed similar phenomena during directional solidification of Bi-Sn alloy under a static magnetic field. These experimental results suggest another effect of static magnetic field which produces flows in the melt during solidification of metals, the so-called the thermoelectric magnetohydrodynamic flows (TEMHDF).

TEMHDF had been recognized in early 1950s' while magnetohydrodynamic scientists studying the transmission problem of liquid metal coolant in the fission 
generator. ${ }^{[15,16]}$ In metallurgy, although Shercliff had theoretically proposed that TEMHDF could appear when applying the magnetic field to metallurgical process in $1979,{ }^{[17]}$ the first report on the existence of TEMHDF in the static magnetic field-assisted solidification of metals was proposed by Moreau et al. till 1991. ${ }^{[14]}$ They found new macro-segregations formed in the Bi-Sn sample directionally solidified under a static magnetic field. After that, TEMHDF in the static magnetic field-assisted solidification caught more attentions. Moreau et al. continued their works and proposed a method to interfere the interdendritic convections via the TEMHDF in mushy zone. ${ }^{[18]}$ Golovanov et al. considered the continuous casting of steel and found that TEC existed, and the induced magnetic fields could cause some anisotropy during solidification. ${ }^{[19]}$ In 2002, Liu suggested that TEMHDF might occur when the directional solidification of Al-based alloys conducted under a static magnetic field. ${ }^{[20]}$ Yasuda from Japan implemented the first attempt to observe in-situ TEMHDF in $2009^{[21]}$ and found that equiaxed grains in front of the solid-liquid interface began to move when switched on a $0.45 \mathrm{~T}$ transverse static magnetic field during solidification of $\mathrm{Sn}$ alloy. He attributed this grain movement to the appearance of TEMHDF because they have the same moving direction. By means of numerical simulation Pericleous and Kao demonstrated that TEMHDF could change the dendritic morphology during ultrahigh undercooling solidification. ${ }^{[22]}$ We also noticed the TEMHDF in static magnetic field-assisted solidification, and previous experimental studies indicated that TEMHDF might cause the change of first and secondary dendritic arm spacing, ${ }^{[23]}$ enhance the split of dendritic tips, ${ }^{[24]}$ affect the instability of solid/liquid interface ${ }^{[25]}$ result in new macro-segregations in DZ417 superalloys, ${ }^{[2]}$ and lead to the formation of annual rings like transverse section structure in $\mathrm{Al}-\mathrm{Cu}$ single-phase alloy. ${ }^{[27]}$ For the first time, Wang et al. ${ }^{[28]}$ gave a visualized evidence for the existence of TEMHDF during directional solidification of metallic alloys under a static magnetic field.

Although massive studies on TEMHDF in solidification have been done, interpretation of TEC in the context of solidification phenomenon is still lacking. And on the numerical simulations aspect, a comprehensive 3D analysis of flow and segregation in vertical Bridgman crystal growth under both axial and transversal magnetic fields can be found ${ }^{[29]}$ but the TEMHDF were not considered. The present work is aiming at fulfilling those lacks and extending our knowledge on TEMHDF and their influence on the solidification under static magnetic field. In this paper, a physical model is proposed to illustrate how the TEC occur at the solid-liquid interface during directional solidification of metallic alloys and verified by a numerical simulation. The influence of TEMHDF on the solid-liquid interface shape is studied through both ex-situ experiments and in-situ observations. Simulations of TEMHDF are performed for both ex and in-situ cases in 3D and indicate that the change of interface shape revealed by the experiments and real-time observations may be attributed to the existence of TEMHDF in the directional solidification conducted under a static magnetic field. Finally, TEMHDF produced by an axial magnetic field are computed and their impacts on the interface shape are predicted. The prediction well agrees with the published experimental results. ${ }^{[30]}$

\section{EXPERIMENTAL DETAILS}

\section{A. Ex-Situ Experiments}

The magnetic field-assisted directional solidification apparatus is represented in Figure 1(a). It consists of an electromagnet and a modified Bridgman-Stockbarger furnace. The electromagnet can provide both alternating and static transverse magnetic field up to $0.7 \mathrm{~T}$ and work for long duration at $0.5 \mathrm{~T}$. The furnace is equipped with pulling down and liquid metal cooling systems. It comprises of nonmagnetic materials with negligible effect on the field uniformity, and its temperature can reach $1273.15 \mathrm{~K}\left(1000^{\circ} \mathrm{C}\right)$ with $\pm 1 \mathrm{~K}\left( \pm 1{ }^{\circ} \mathrm{C}\right)$ accuracy. A water-cooled cylinder containing Ga-In-Sn liquid metal is used to cool down the sample and it is insulated from the furnace by a refractory disk. The directional solidification was realized by pulling down the re-melted sample into the liquid metal pool at a constant speed that can vary from 0.5 to $5000 \mu \mathrm{m} / \mathrm{s}$. The thermal gradient in the sample was controllable by adjusting the furnace temperature. In order to freeze the morphology of solid-liquid interface, the sample was quenched when its steady growth had lasted for a certain time. To clarify the interface shape, a planar solid-liquid interface was expected and thus low pulling down speed of $0.6 \mu \mathrm{m} / \mathrm{s}$, high thermal gradient of $6000 \mathrm{~K} / \mathrm{m}$ $\left(6000{ }^{\circ} \mathrm{C} / \mathrm{m}\right)$, and a dilute Al-0.85wt petCu alloy were used for the ex-situ experiments.

The Al-0.85wt pctCu alloy used in ex-situ experiments was prepared with high-purity $\mathrm{Al}$ (99.99 pct) and $\mathrm{Cu}$ (99.99 pct). The master alloy was placed in a high-purity graphite crucible with $100 \mathrm{~mm}$ diameter and melted by an electromagnetic induction furnace under the argon gas protecting. Several melt-solidification cycles were performed to ensure the master alloys' homogeneity. The cylindrical samples with $3 \mathrm{~mm}$ diameter and $200 \mathrm{~mm}$ length were cut off from the master alloy ingot using wire electrical discharge machining. The prefabricated sample was enveloped in a high-purity corundum tube with $3 \mathrm{~mm}$ inner diameter and $250 \mathrm{~mm}$ length for the experiment. The morphologies of solid-liquid interface obtained under different transverse magnetic fields were examined by the optical microscopy, and the $\mathrm{Cu}$ solute distributions in front of the solid-liquid interface were characterized by the electron probe micro analyzer (EPMA).

\section{B. In-Situ Observations}

The in-situ observations of static magnetic field-assisted directional solidification were achieved by means of synchrotron X-ray radiography. These live observations were taken on the BM05 beamline at European Synchrotron Radiation Facility (ESRF, Grenoble). The photo of the apparatus for real-time observation and its 


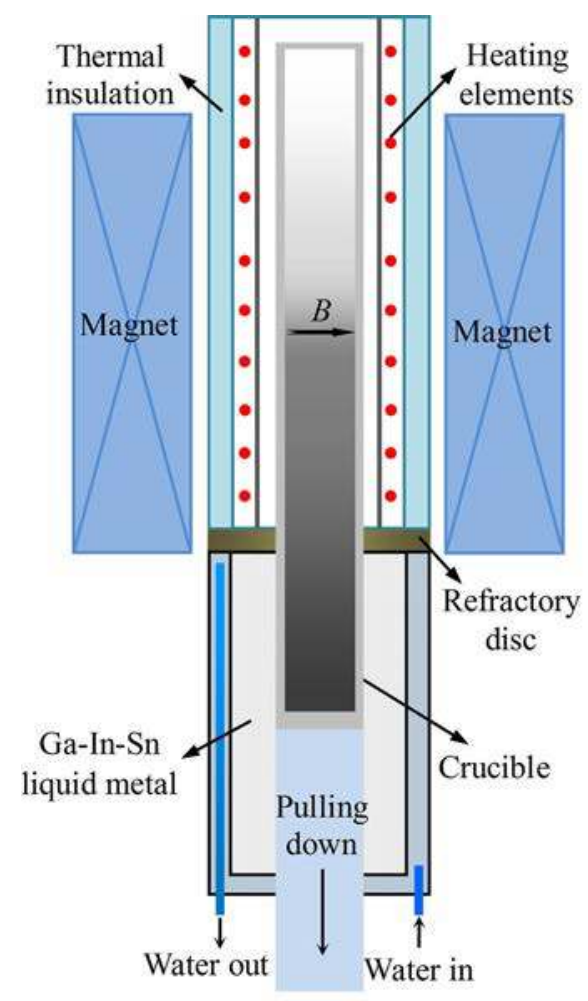

(a)
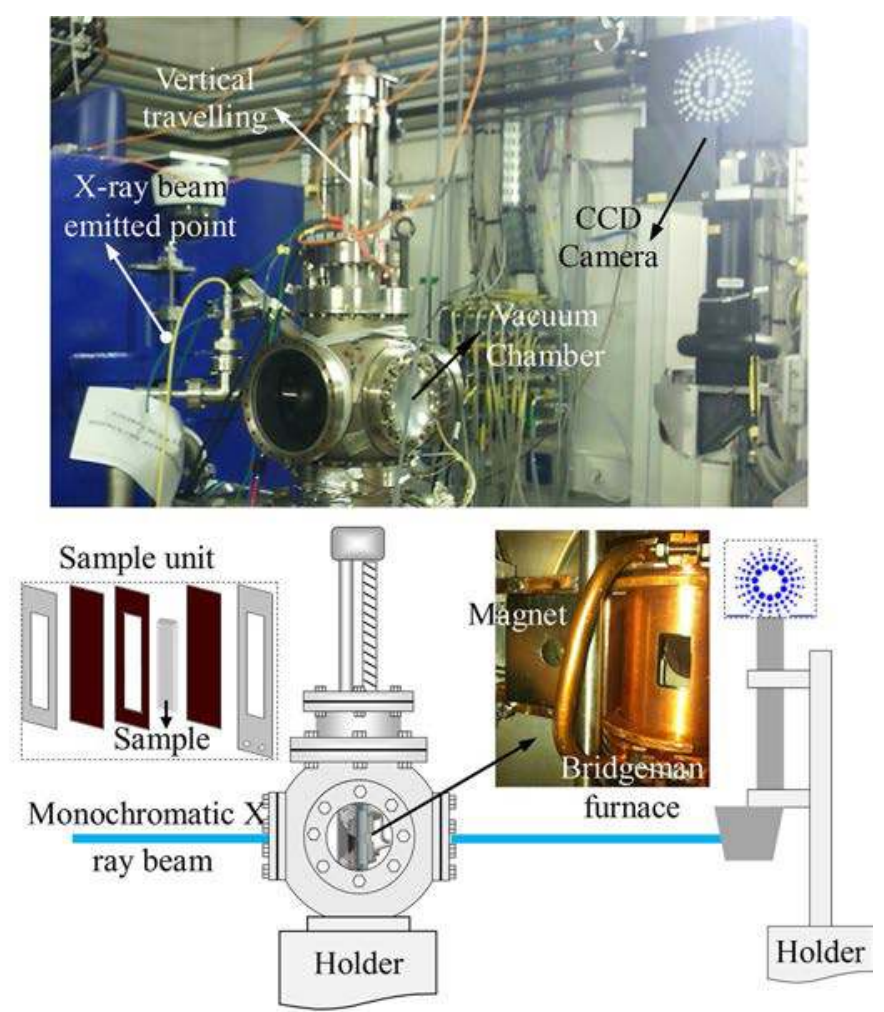

(b)

Fig. 1-(a) Sketch of magnetic field assisting directional solidification apparatus; (b) Photo and sketch of the synchrotron X-ray radiography apparatus for real time observing the directional solidification of Al-4wt pctCu alloy conducted without and with a static magnetic field.

corresponding sketch are shown in Figure 1(b). A $17.5 \mathrm{keV}$ monochromatic beam was used to achieve the sufficient transmission and good contrast between liquid and solid phases, because the contrast of the X-ray image highly depends on the element atomic number and the solute concentration. The detector was the fast readout-low noise CCD camera developed at ESRF, which can obtain a good compromise between large field of view $\left(15 \times 6 \mathrm{~mm}^{2}\right)$ and satisfying spatial resolution (pixel size: $7.46 \times 7.46 \mu \mathrm{m}^{2}$ ). The high intensity of synchrotron radiation makes it possible to record images with enough contrast in a reasonable timescale $(0.7 \mathrm{~s}$ in our study), and thus enable the researches on solidification kinetics.

The Al-4wt pctCu alloy fabricated from pure $\mathrm{Al}$ and $\mathrm{Cu}$ element was used in these in-situ observations. This is because it can provide good image contrast than Al- $0.85 \mathrm{wt}$ pctCu alloy and in the same time its planar solid-liquid interface is achievable with reasonable processing conditions $\left(0.1 \mathrm{~K} / \mathrm{min}\left(0.1^{\circ} \mathrm{C} / \mathrm{min}\right)\right.$ cooling rate and $3500 \mathrm{~K} / \mathrm{m}\left(3500{ }^{\circ} \mathrm{C} / \mathrm{m}\right)$ thermal gradient). The cuboid samples with $200 \mu \mathrm{m}$ in thickness, $6 \mathrm{~mm}$ in width, and $40 \mathrm{~mm}$ in length were cut off from the master alloy ingot. The prefabricated sample sandwiched between two graphite foils was fixed between two molybdenum diaphragms by two clips, and such assembled unit was vertically placed in the center of the Bridgman furnace for experiment. The directional solidification was realized by a 'power down' method applying the same cooling rate on both hot and cold zone heating elements during the entire experiment. This method ensured a constant thermal gradient and growth rate during directional solidification. As shown by the photo inserted in the sketch in Figure 1(b), a sintered $\mathrm{NbFeB}$ permanent magnet mounted close to the Bridgman furnace was used and provided a uniform $0.08 \mathrm{~T}$ transverse static magnetic field within the sample. The recorded images were analyzed by a free code ImageJ.

\section{THERMOELECTRIC CURRENTS IN DIRECTIONAL SOLIDIFICATION}

\section{A. Physical Model}

According to the Seebeck-Thomson effect, thermoelectric currents (TEC) can appear when two junctions of a closed loop made by two dissimilar conducting materials are placed in different temperatures as illustrated by the sketch inserted in Figure 2(d). In fact phenomena near to the solid-liquid interface during solidification meet all these demands. This is because, in general, all materials manufactured by solidification have thermal gradient along the solid-liquid interface (because the melting temperature is solute concentration dependent and that cannot be uniform in the melt ahead the solid-liquid front in practice), and the thermal physical properties of their liquid and solid phases are different such as the thermal and electrical conductivities 
and the absolute thermoelectric powers. The thermal gradient provides temperature differences between junctions and the solid and liquid phases can act as two dissimilar conducting materials due to their property differences. Therefore, TEC are inherent in solidification of metals. As marked by the white rectangles in Figure 2(a) through (c), small cells from typical planar, cellular, and dendritic interfaces were selected and simplified into a curved solid-liquid interface (Figure 2(d)) to illustrate the TEC in solidification. In these cases, temperature differences between interface top and bottom together with the property differences between solid and liquid phases give rise to the TEC that flow in a pattern like the black-dotted circle in Figure 2(d). It indicates that TEC exist in both liquid and solid phases and close their loop via flowing cross the solid-liquid interface. One thing is noteworthy that as highlighted by the red and blue spots at the interface in Figure 2(d), Peltier heating/cooling effect could appear when TEC cross over and Thomson effect could occur in the solid and liquid phases individually. These two effects are out of this paper's discussion range, and in fact their impacts are negligible ${ }^{[31]}$ in most of the solidifications. However, it is worthy to mention that the Peltier effect had been a sufficient method to in-situ mark the solid-liquid interface profile during solidification of metals ${ }^{[32,33]}$ before the synchrony X-ray observation appears.

\section{B. Numerical Method and Simulations}

To calculate electric currents at solid-liquid interface during directional solidification, a complementary term should be added to Ohm's law:

$$
\vec{j}=-\sigma(\vec{\nabla} V+S \vec{\nabla} T),
$$

where $V$ is the electric scalar potential, $S$ is the absolute thermoelectric power, and $\vec{\nabla} T$ denotes the thermal gradient. The second term at this equation's right hand is the contribution of TEC. The electric current density satisfies to the continuity equation:

$$
\vec{\nabla} \cdot \vec{j}=0 .
$$

Equations [1] and [2] both are valid in the liquid and in the solid. It should be pointed out that another complementary term, $\vec{u} \times \vec{B}(\vec{u}$ is the fluid velocity field and $\vec{B}$ is the applied magnetic field), should be added to Eq. [1] when magnetic field is present because this gives the electric currents induced by the conducting melt moving across the magnetic field lines. Equations [1] and [2] are solved in terms of the electric scalar potential $V$ in both liquid and solid. More details about the equations and corresponding boundary conditions can be found in Reference 34 . With a fixed and prescribed solid-liquid interface, this system is solved both in liquid and solid phases simultaneously by a commercial finite element code COMSOL Multiphysics using its packed electric current module. It should be mentioned that using a given interface is to propose a heuristic model but not

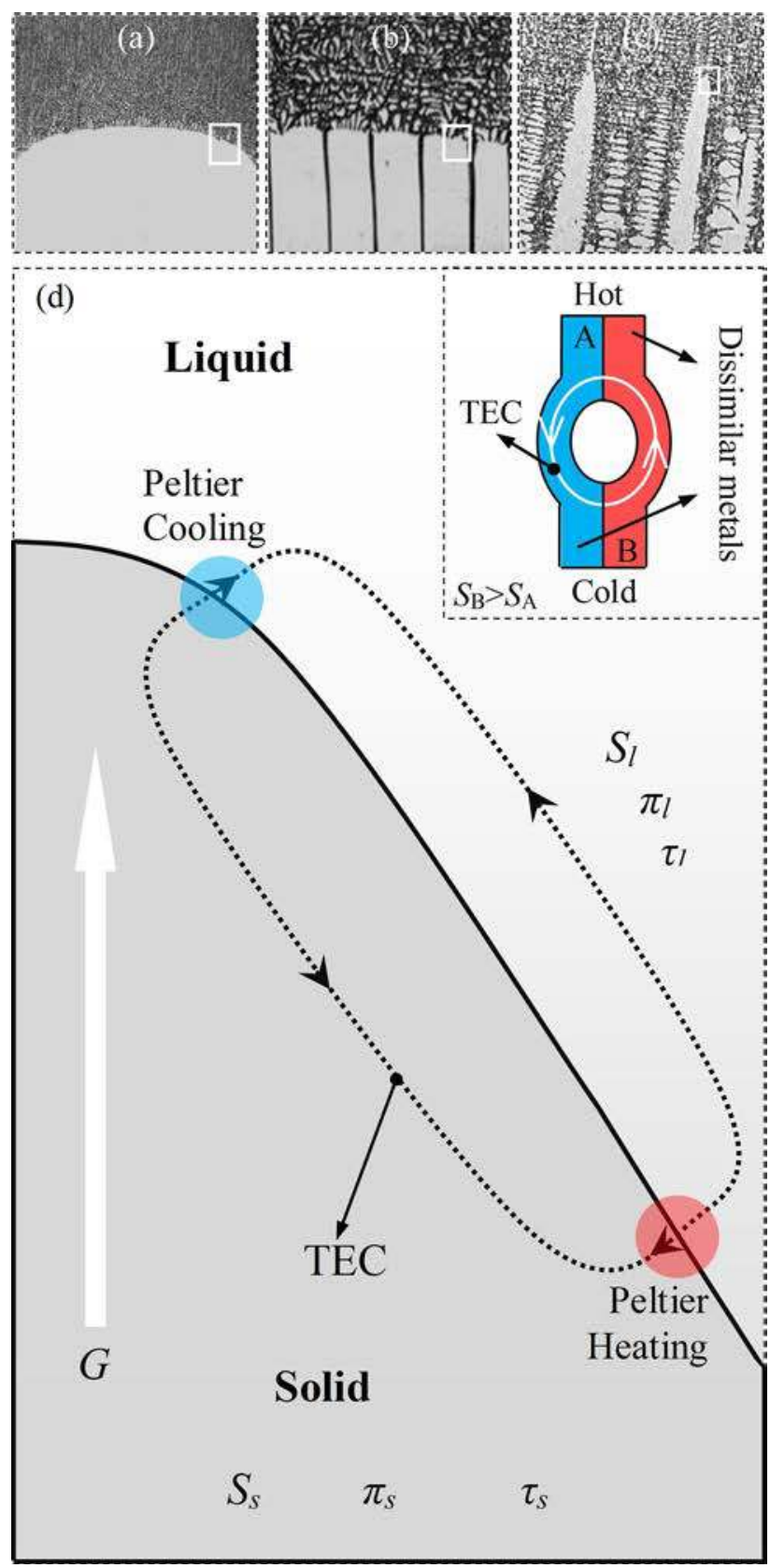

Fig. 2-(a) Planar interface obtained during directionally solidifying the $\mathrm{Al}-0.85 \mathrm{wt}$ petCu alloy at a $1 \mu \mathrm{m} / \mathrm{s}$ pulling down speed and a $6300 \mathrm{~K} / \mathrm{m}\left(6300^{\circ} \mathrm{C} / \mathrm{m}\right)$ thermal gradient; $(b)$ Cellular interface obtained during directionally solidifying the $\mathrm{Al}-0.85 \mathrm{wt} \mathrm{pctCu}$ alloy at a $2 \mu \mathrm{m} / \mathrm{s}$ pulling down speed and a $6300 \mathrm{~K} / \mathrm{m}\left(6300{ }^{\circ} \mathrm{C} / \mathrm{m}\right)$ thermal gradient; $(c)$ Dendritic interface obtained during directionally solidifying the DZ417 superalloy at a $5 \mu \mathrm{m} / \mathrm{s}$ pulling down speed and a $15,000 \mathrm{~K} / \mathrm{m}\left(15000{ }^{\circ} \mathrm{C} / \mathrm{m}\right)$ thermal gradient; (d) Illustration of TEC at solid-liquid interface during directional solidification of metals $(G$ is thermal gradient, $S$ is the absolute thermoelectric power, $\pi$ is the Peltier coefficient, $\tau$ is the Thomson coefficient, and the subscripts $l$ and $s$ represent the liquid and solid phases, respectively).

standing for any kinds of the real solid-liquid interface, and qualitatively illustrate how the TEC and TEMHDF generate, behave, and their impacts on the solute distribution around the solid-liquid interface. 


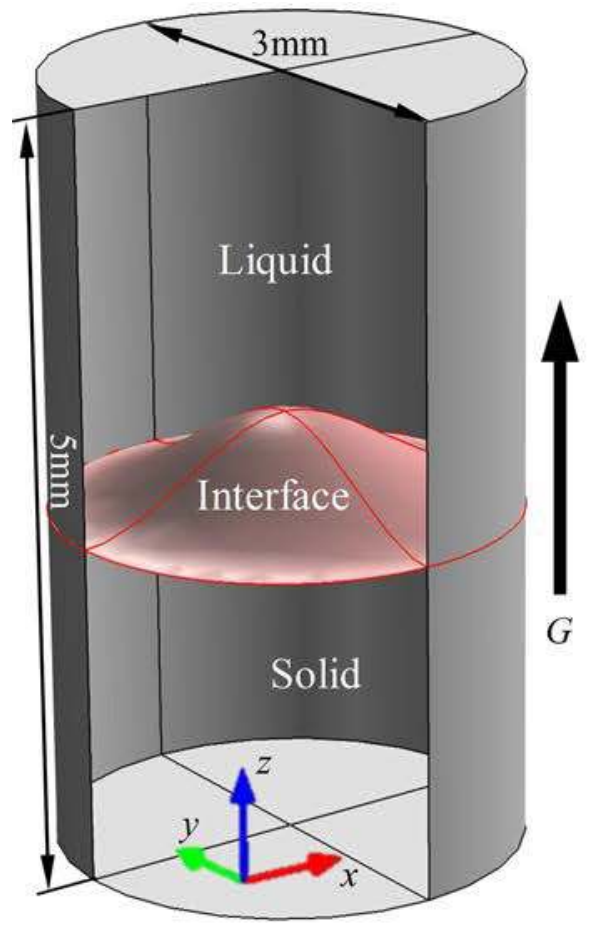

(a)

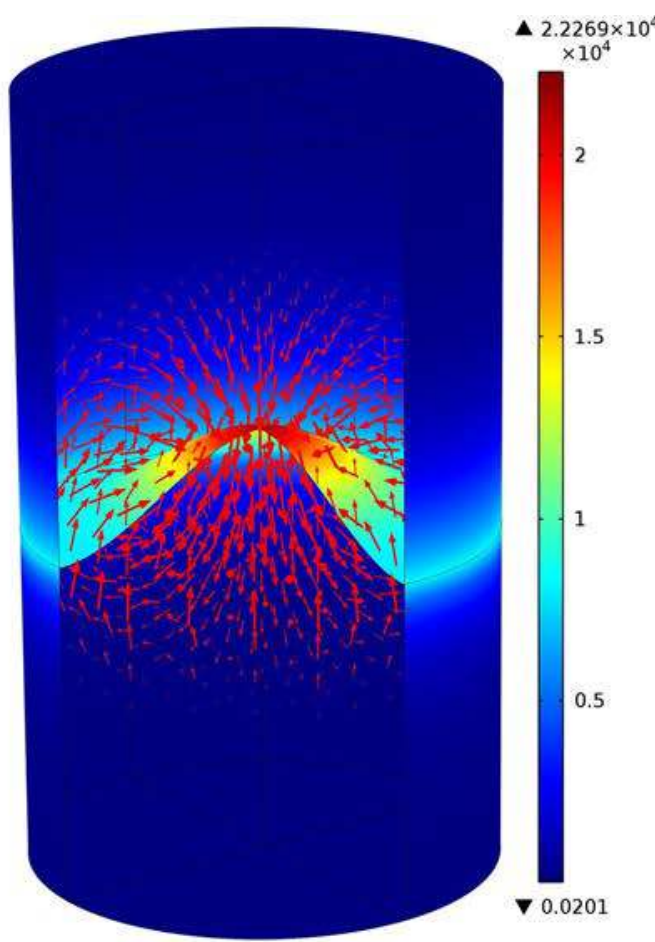

(b)

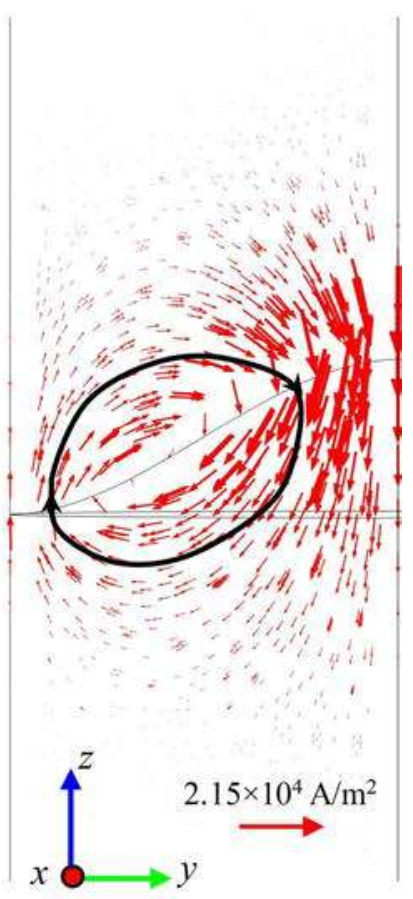

(c)

Fig. 3- (a) 3D Geometry of the domain used in the simulation of TEC produced by a upward constant thermal gradient of $6000 \mathrm{~K} / \mathrm{m}\left(6000{ }^{\circ} \mathrm{C} /\right.$ $\mathrm{m}$ ) and its dimensions; $(b)$ Red arrows show the 3D distribution of computed TEC around the solid-liquid interface and the colored surfaces present their magnitudes (the unit in caption is $\left.\mathrm{A} / \mathrm{m}^{2}\right) ;(c)$ Red arrows proportioned to TEC's magnitudes show the flowing pattern of computed TEC in a $\mathrm{y}-\mathrm{z}$ plane near the solid-liquid interface, and the black circle with arrows is drawn to clarify the TEC loop.

Table I. Parameters Used in Simulations

\begin{tabular}{llll}
\hline Name and Symbol & \multicolumn{1}{c}{ Unit } & \multicolumn{1}{c}{ Solid } & Liquid \\
\hline Absolute thermoelectric power $(S)$ & $\mathrm{V} / \mathrm{K}\left(\mathrm{V} /{ }^{\circ} \mathrm{C}\right)$ & $-1.5 \times 10^{-6}$ & $-2.25 \times 10^{-6}$ \\
Electrical conductivity $(\sigma)$ & $(\Omega \mathrm{m})^{-1}$ & $7.9 \times 10^{7}$ & $4.0 \times 10^{6}$ \\
Dynamic viscosity $(\mu)$ & $\mathrm{Pa} \mathrm{s}$ & $-2.7 \times 10^{3}$ & $2.9 \times 10^{-3}$ \\
Density $(\rho)$ & $\mathrm{kg} / \mathrm{m}^{3}$ & 150 & $2.4 \times 10^{3}$ \\
Thermal conductivity $(\lambda)$ & $\mathrm{W} /(\mathrm{m} \mathrm{K})\left(\mathrm{W} /\left(\mathrm{m}{ }^{\circ} \mathrm{C}\right)\right)$ & 95 \\
\hline
\end{tabular}

Figure 3(a) shows the geometry used to perform the simulation of TEC and its dimensions. With the purpose to make the simulation closer to the practice situation, a 3D cylindrical domain with $3 \mathrm{~mm}$ in diameter was used and created by revolving a $2 \mathrm{D}$ structure similar to the one shown in Figure 2(d). Using the parameters listed in Table I, TEC produced by a constant upward thermal gradient of $6000 \mathrm{~K} / \mathrm{m}\left(6000{ }^{\circ} \mathrm{C} / \mathrm{m}\right)$ was computed. Figure 3(b) shows the 3D distribution of computed TEC and their magnitudes are presented by the red arrows and colored surface, respectively. It indicates that TEC is axisymmetric around the vertical axis. Both the scarce arrows and dark blue color in the regions apart from the interface suggest that there are no TEC either in the bulk liquid or solid far from the interface. This can attribute to the assumption that the absolute thermoelectric power in either solid or liquid is constant, whereas the occurrence of Seebeck-Thomson effect relies on their difference. To display the TEC flow pattern more clearly, their distribution near solid-liquid interface is shown in a $y-z$ plane in Figure 3(c). It demonstrates that TEC flow from the solid to the liquid phase at the periphery and flow back at the interface's center area. Such flow pattern increases the current density at the top-center of the convex solid-liquid interface as revealed by the red surfaces in Figure 3(b). The loop of computed TEC emphasized by the black circle with arrows in Figure 3(c) is perfect in line with the one shown in Figure 2(d), providing a mutual confirmation for the proposed physical model.

\section{EX-SITU EXPERIMENTS AND CORRESPONDING SIMULATIONS}

\section{A. Experimental Results and Discussions}

Interacting with the superimposed static magnetic field TEC in liquid can produce TEMHDF, and their influences on directional solidification of alloys were investigated experimentally in this paper first. The 
Al- $0.85 \mathrm{wt}$ pctCu alloys were directionally solidified under various transverse static magnetic fields at an unchanged thermal gradient of $6000 \mathrm{~K} / \mathrm{m}\left(6000{ }^{\circ} \mathrm{C} / \mathrm{m}\right)$ and pulling down speed of $0.6 \mu \mathrm{m} / \mathrm{s}$. By quenching and vertically cutting the samples, Figure 4(a) through (d) display the longitudinal structures of the solid-liquid interfaces obtained under different magnetic fields. In the case without magnetic field, the selected processing conditions enable a stable planar solid-liquid interface and its shape is nearly flat as shown in Figure 4(a). Applying a weak transverse static magnetic field of only $0.05 \mathrm{~T}$ has no apparent effect on solid-liquid interface morphology but dramatically changes its global shape leading to sag of the interface at its right side as shown in Figure 4(b). Increasing the magnetic field to $0.1 \mathrm{~T}$, the planar morphology of the interface does not change, while its sagged degree on the right side decreases (Figure 4(c)). As shown in Figure 4(d), an even planar interface is obtained when the applied magnetic field is raised to $0.3 \mathrm{~T}$. It is widely accepted that the solid-liquid interface distortion can attribute to the solute segregation ahead, ${ }^{[35]}$ and in fact the appearance of pits (indicated by the white arrows in Figure 4(b) through (c) also suggests a solute enrichment in front of the sagged interface because the interface instability occurs when the solute concentration is higher. ${ }^{[36]}$ To further confirm the solute segregation $\mathrm{Cu}$ content along a horizontal line (indicated by the black-dotted arrow in Figure 4(a), (b), and (d) that $1 \mathrm{~mm}$ below the solid-liquid interface's flat part was detected by the electron probe micro analyzer (EPMA). The results shown in Figure 4(e) demonstrate that the solute segregation under a $0.05 \mathrm{~T}$ transverse static magnetic field is severe and the $\mathrm{Cu}$ distributes uniformly in the samples obtained without and with the $0.3 \mathrm{~T}$ magnetic field. This agrees well with the change of interface shape. Such solute segregations indicate 'new flows' in the melt transporting the rejected solutes to one side of the solid-liquid interface. These one side flowing flows cannot be the natural convections in directional solidification because their flow patterns are different, and in another aspect natural convections in the melt should be damped by the transverse static magnetic field. The slight sagged interface obtained under $0.1 \mathrm{~T}$ magnetic field suggests low speed of the 'new flows' under a magnetic field higher than $0.05 \mathrm{~T}$, and the even planar interface under a $0.3 \mathrm{~T}$ magnetic field means that the flow disappears under much higher static magnetic field. These experimental results suggest that with constantly increasing static magnetic fields such 'new flows' have a similar speed change tendency compared to the TEMHDF, which is speeding up first to a maximum velocity and being damped by the further increasing magnetic fields. ${ }^{[17,23]}$ For the reasons mentioned above, the 'new flows' revealed by these ex-situ experiments are considered to be the TEMHDF.

As shown in Figure 4(f), the magnified view of interface within the white-dotted box in Figure 4(a) exhibits perturbations of the interface leading to a wavy solid-liquid interface. Because of curvature effects, this may give rise locally to TEC in accordance with the physical model introduced above. Indeed, the curved periphery of solid-liquid interface indicated by the white solid box in Figure 4(a) can be another source of TEC. The curved periphery is more visible in the magnified view of Figure $4(\mathrm{~g})$. Considering these reasons, it is more likely to attribute the solute segregation/sagged interface obtained under a weak transverse static magnetic field to the TEMHDF.

\section{B. Computed Results and Discussions}

Numerical simulations were carried out in order to confirm that TEMHDF produced by a transverse static magnetic field in our experiments could have the one-direction flow pattern at the vicinity of solid-liquid interface. The finite element method-based code COMSOL Multiphysics was used, and the pre-packed heat transfer, electric current, and fluid flow modules were coupled. The prescribed interface structure is curved near the side wall as shown in Figure 5(a). It was to be known that this model only considered solid-liquid interface curved periphery feature as indicated by the inserted picture in Figure 5(a). The electric currents density $(\sigma(\vec{u} \times \vec{B}))$ induced by the melt motion was considered in these simulations because it can generate damping forces when computing the fluid flow. The damping effect may occur because its quantification that the Hartmann number ${ }^{[34]} H a=B L(\sigma / \mu)^{1 / 2} \approx 2.78$ is bigger than unity for the conditions these simulations use ( $B=0.05 \mathrm{~T}$ and the typical length $L=1.5 \mathrm{~mm}$ ). Using the parameters in Table I and setting different temperatures to the top $983.15 \mathrm{~K}\left(710^{\circ} \mathrm{C}\right)$ and bottom $953.15 \mathrm{~K}\left(680^{\circ} \mathrm{C}\right)$ of the domain, temperature distribution in the sample was computed by the heat transfer module and shown by the colored surfaces in Figure 5(b). Coupling the electric current module, the current density (TEC) was computed and its distribution is shown by arrows in Figure 5(b). As emphasized by the inserted picture which provides a magnified view of the region within the black-dotted circle, TEC exist in the vicinity of the solid-liquid interface and flow through both solid and liquid phases. Moreover, we computed the fluid flow generated by the Lorentz forces induced by interaction between TEC and a $0.05 \mathrm{~T}$ transverse static magnetic field. The magnitudes of these forces are given by a colored $y-z$ plane in Figure 5(c). It is clear that the strongest forces are at interface's curved periphery and are orientated toward to the negative $x$-axis direction as revealed by the inserted picture. The computed flow field of TEMHDF is shown by red arrows in Figure 5(c). It indicates that TEMHDF flow from the positive $x$-axis to negative at the periphery and then go up to form the backflows mainly in bulk liquid center. These red arrows' lengths suggest that the most intense flows appear at solid-liquid interface's curved periphery. Transported by such one-direction global TEMHDF motion, the rejected solutes may concentrate at one side of the interface like the region indicated by the yellow circle with dots in Figure 5(c). Figure 5(d) shows the flow field near the solid-liquid interface's curved periphery in the view similar to the metallography in Figure 4. It can be seen that these TEMHDF 

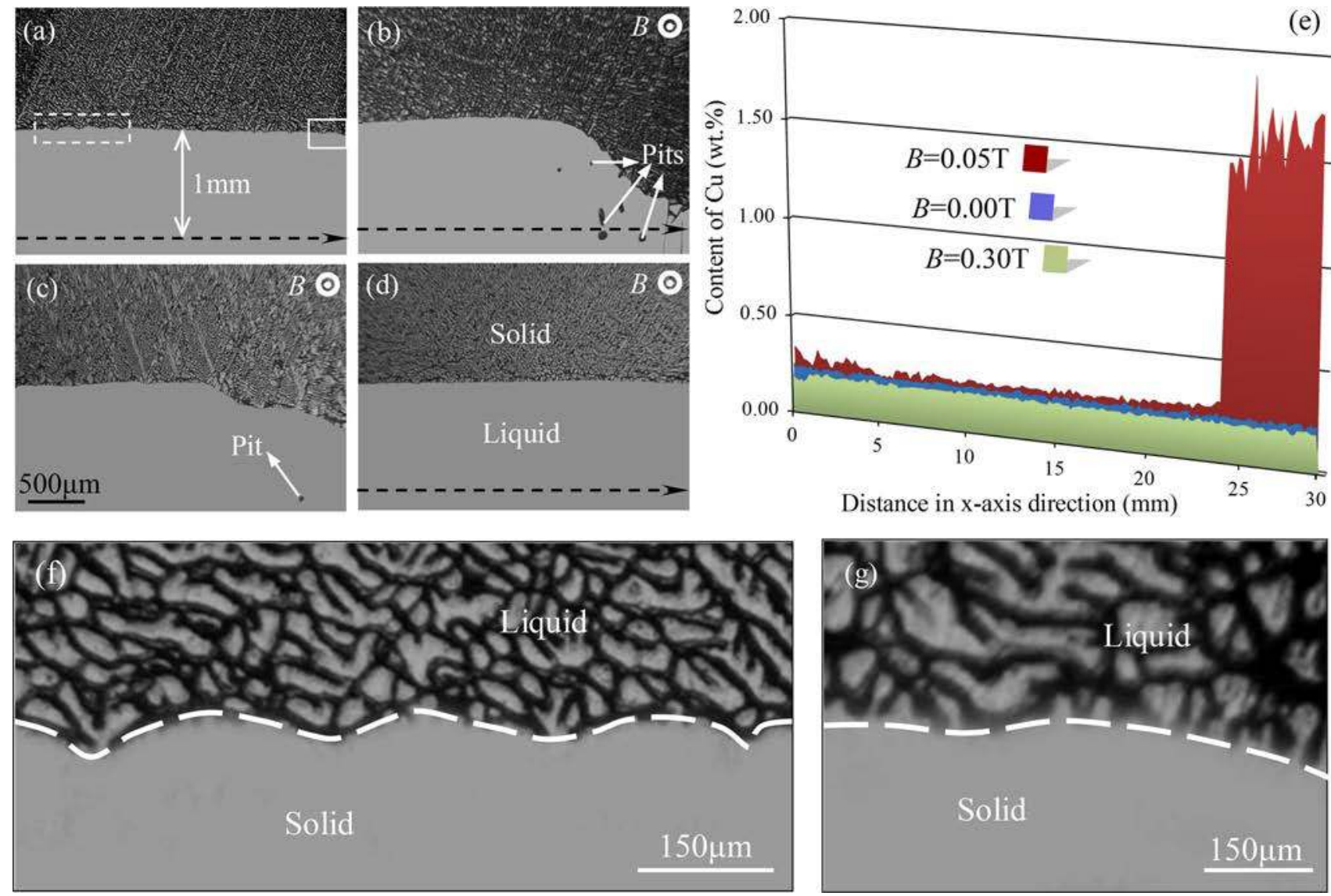

Fig. 4-Longitudinal (parallel to the growth direction and perpendicular to the magnetic field direction) structures of planar interfaces obtained during directionally solidifying a $\mathrm{Al}-0.85 \mathrm{wt}$ pctCu alloys under different transverse static magnetic field values, the pulling down speed is $0.6 \mu \mathrm{m} /$ $\mathrm{s}$, and thermal gradient is $6000 \mathrm{~K} / \mathrm{m}\left(6000{ }^{\circ} \mathrm{C} / \mathrm{m}\right),(a) B=0 \mathrm{~T} ;(b) B=0.05 \mathrm{~T} ;(c) B=0.1 \mathrm{~T} ;(d) B=0.3 \mathrm{~T} ;(e)$ EPMA results of Cu content along a horizontal line that $1 \mathrm{~mm}$ below the flat part of solid-liquid interface; ( $f$ ) Magnified view of the interface within the white-dotted box in (a); $(g)$ Magnified view of the interface within the white solid box in (a).

flow in one direction from the left to right may transport the solutes to interface's right part at where the distortion forms. The solute accumulation increases the solidification deformation by decreasing locally the front growth kinetics. This agrees well with the ex-situ experiments. The chemical Péclet number $P e=U L / D$ $\approx 40.24$ (with $U=107.3 \mu \mathrm{m} / \mathrm{s}$ the average velocity of computed TEMHDF, $L=1.5 \mathrm{~mm}$, and $D=4 \times$ $10^{-9} \mathrm{~m}^{2} / \mathrm{s}$ diffusion coefficient of $\mathrm{Cu}$ element in the melt) is much bigger than unity. This confirms that these TEMHDF were sufficient to transport the solutes on one side of the solid-liquid interface.

\section{IN-SITU OBSERVATIONS AND CORRESPONDING SIMULATIONS}

\section{A. Observations and Discussions}

In order to get more definite evidence for TEMHDF and their influences on the shape of solid-liquid interface, in-situ and real-time observations of directional solidification of $\mathrm{Al}-4 \mathrm{wt}$ petCu without and with a $0.08 \mathrm{~T}$ transverse static magnetic field were carried out by means of synchrotron X-ray radiography.
Figure 6(a) shows interface's profiles at different moments during solidification, illustrating its shape evolution with time in the case without magnetic field. In the early stage (e.g., $\left.t=t_{0}\right)$, the solid-liquid interface is slightly tilted to the right due possibly to the unavoidable radial thermal gradient in practice. The profiles obtained at $t_{1}$ to $t_{5}$ exhibit a more and more tilted interface as the directional solidification proceeded. This could attribute to solute accumulation in the depressed part of solid-liquid interface. Firstly, considering that $\mathrm{Cu}$ is rejected at the solid-liquid interface during solidification of single-phase $\mathrm{Al}-\mathrm{Cu}$ alloy, sinking of the denser $\mathrm{Cu}$-enriched melt due to gravity may occur. Secondly, solute transported by a thermal-solutal convection could be the other way because such convection has a top-to-bottom flow pattern (as indicated by the black-dotted line with arrows in Figure 6(a)) and thus accumulates the solutes in front of interface's depressed part. The top-to-bottom convection is understandable because the initially depressed interface suggests a higher temperature nearby compared to the other places, consequently the melts raise near to interface's bottom and flow back from its top. ${ }^{[37]}$ When a $0.08 \mathrm{~T}$ transverse static 


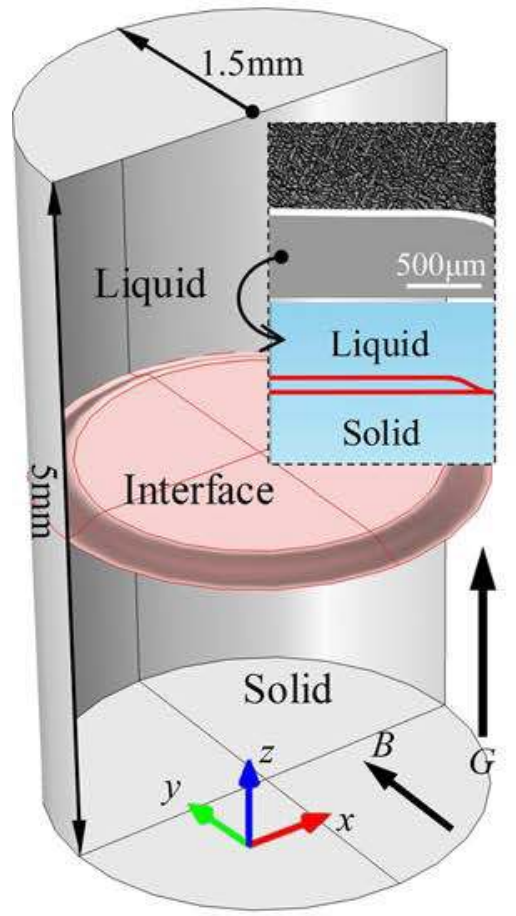

(a)

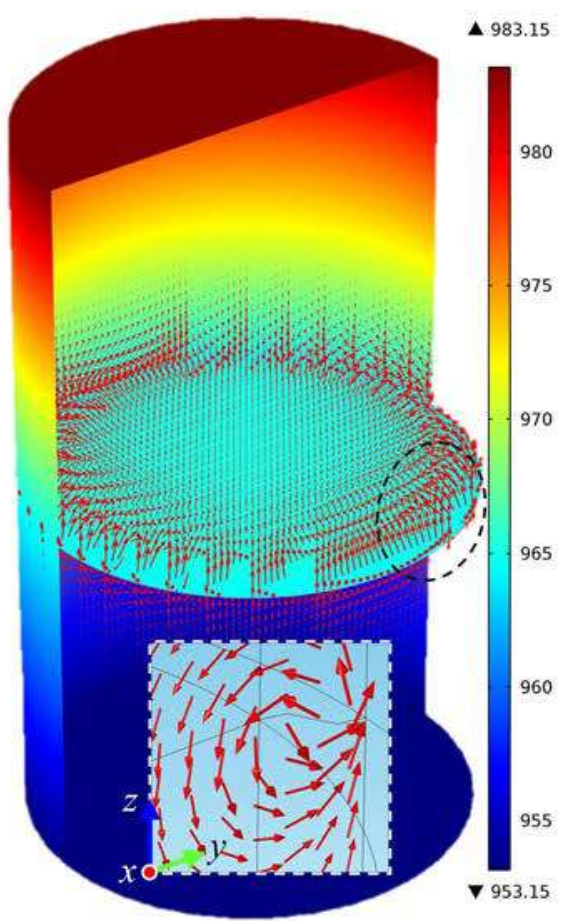

(b)
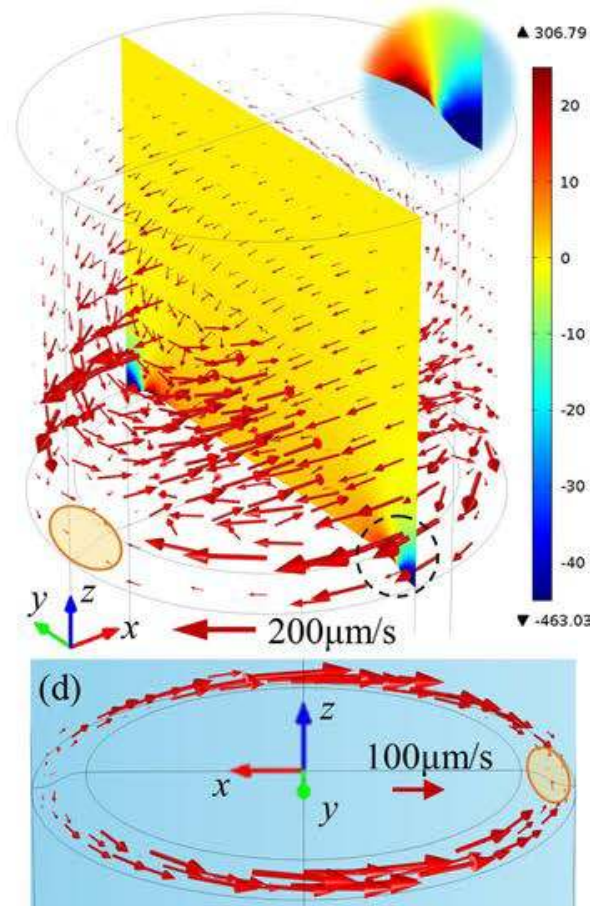

(c)

Fig. 5- (a) Geometry of the domain and its dimensions used for the simulation of TEMHDF under a 0.05 T transverse static magnetic field (B) and a upward thermal gradient of $6000 \mathrm{~K} / \mathrm{m}\left(6000^{\circ} \mathrm{C} / \mathrm{m}\right)(G)$, the similarity between the prescribed and real solid-liquid interface is revealed by the inserted picture; $(b)$ The colored surfaces are the computed temperature distribution within the sample and red arrows present TEC, the inserted picture is the magnified view of the region marked by the black-dotted circle (the unit in caption is $\mathrm{K}$ ); $(c)$ The colored $y$ - $z$ plane presents the magnitudes of Lorentz forces caused by interaction between the TEC and a $0.05 \mathrm{~T}$ transverse static magnetic field, the inserted picture is the magnified view of the region marked by the black-dotted circle, and the red arrows show the computed flow field of TEMHDF (the unit in caption is $\left.\mathrm{N} / \mathrm{m}^{3}\right) ;(d)$ The computed TEMHDF within solid-liquid interface's curved periphery shown in the view is similar to the metallography in Figure 4.

magnetic field is applied, the solid-liquid interface is also uneven at the beginning and indeed sagged at its left as shown by the profile at $t_{0}$ moment in Figure 6(b). However, contrary to the case without magnetic field, interface's initially depressed part gradually caught up its top and a nearly flat interface shape was achieved as indicated by its profile at $t_{5}$. This reversed shape evolution of the solid-liquid interface suggests a solute transport from interface's bottom to its top takes place. To visually detect the transport of denser $\mathrm{Cu}$ solutes, the contrasts of radiographies captured at about 130, 190, and $220 \mathrm{~min}$ after the beginning of solidification were analyzed and are shown in Figure 6(c) through 6(e). The dark clouds as delimited by the black-dotted circle in Figure 6(c) represent the region with higher $\mathrm{Cu}$ concentration because the pixels' gray level is a function of solute concentration. ${ }^{[37]}$ As indicated by the white arrows in Figure 6(d), the solutes were progressively transported from interface's bottom-left to the top-right regions. Such solute transport path requests the flows with a bottom-to-top flow pattern like the black-dotted line with arrows in Figure 6(b). This could only be explained by assuming that TEMHDF exists because the thermal-solutal convection flows from the top to bottom and the well-known damping effect of static magnetic field could in the best case just keep interface's initial tilting degree unchanged. The bottom-to-top
TEMHDF flow pattern in this directional solidification of Al-4wt petCu alloy under a $0.08 \mathrm{~T}$ transverse magnetic field was confirmed by its corresponding simulations.

\section{B. Computed Results and Discussions}

Based on the initial interface structure observed in the case with magnetic field experiment, a similar 3D geometry was created and is shown in Figure 7(a) together with its dimensions. One should mention that the solid-liquid interface used for this simulation was convex in $x$-axis direction as indicated by the inserted picture. This is because the simulation would be reduced to a purely $2 \mathrm{D}$ problem if using the interface perfectly flat in $x$-axis direction. In $2 \mathrm{D}$ case, both TEC and their resultant Lorentz forces exist but the forces in the melt are curl-free that cannot generate any flow but only a pressure field. ${ }^{[34]}$ In fact that the solid-liquid interface cannot be perfectly flat in any dimensions due to the formation of a meniscus between the solid, liquid and the crucible. ${ }^{[38]}$ Using the numerical method introduced above and relevant parameters in Table I, we computed TEC induced by a thermal gradient of $3500 \mathrm{~K} / \mathrm{m}$ $\left(3500{ }^{\circ} \mathrm{C} / \mathrm{m}\right.$ ) and the TEMHDF was produced by these TEC interacting with a $0.08 \mathrm{~T}$ transverse static magnetic field. Figure 7(b) is the computed TEC distribution near 

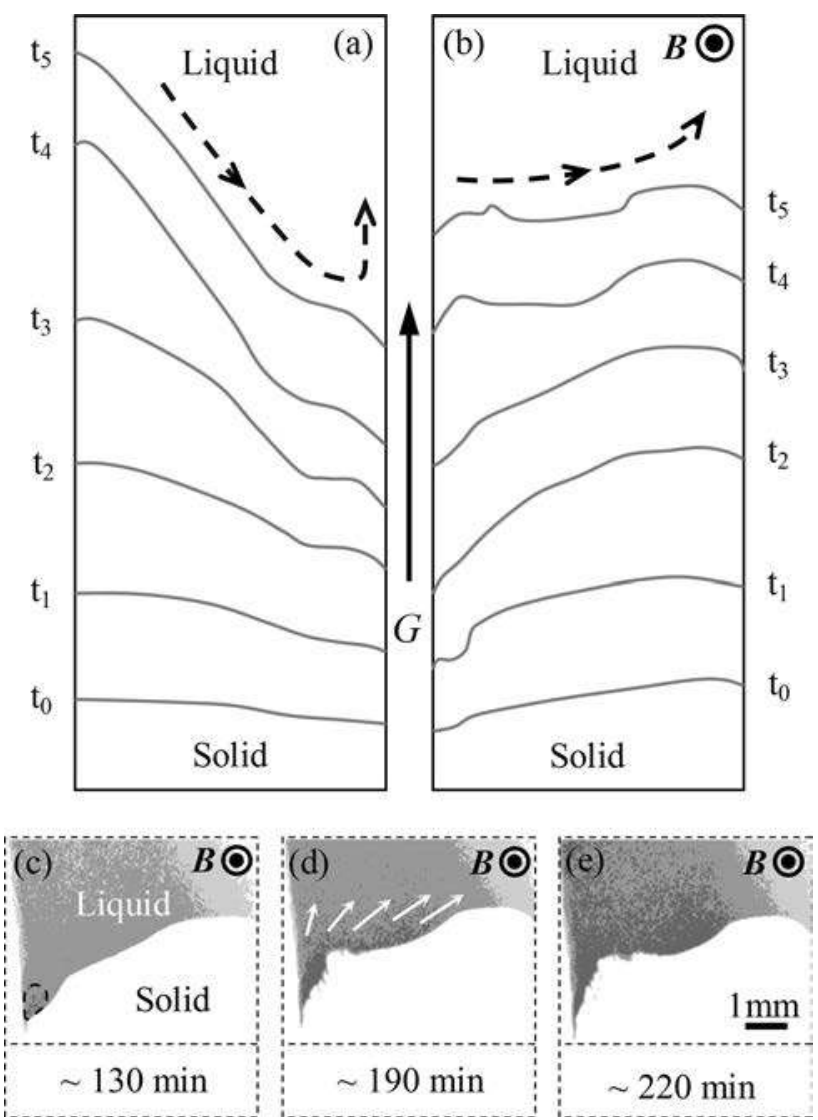

Fig. 6-(a) The solid-liquid interface profiles observed at different moments during the Al-4wt petCu alloy directionally solidified without magnetic field, and the black-dotted line with arrows indicates the flow pattern of thermal-solutal convection; $(b)$ The solid-liquid interface profiles observed at different moments during the $\mathrm{Al}-4 \mathrm{wt}$ pctCu alloy directionally solidified under a $0.08 \mathrm{~T}$ transverse static magnetic field $(B)$, and the black-dotted line with arrows indicates the flow pattern that TEMHDF need to have; (c) The view near solid-liquid interface observed at about $130 \mathrm{~min}$ after the beginning of directional solidification, and the dark clouds delimited by a black-dotted circle present the rejected $\mathrm{Cu}$ solutes; $(d)$ The view near solid-liquid interface observed at about 190 min after the directional solidification began, and the white arrows indicate the solute transport direction; (e) The view near solid-liquid interface observed at about $220 \mathrm{~min}$.

to the solid-liquid interface in an $x-z$ plane, which shows a good agreement with the interpretation given by the physical model. The red arrows proportional to TEC magnitudes indicate that the electric currents flow through both solid and liquid phases and from the periphery to interface's top-center. In Figure 7(c), the red arrows show the computed flow field of TEMHDF and the colored $y-z$ plane indicates their magnitudes. It is clear that TEMHDF under present conditions flow from the bottom of solid-liquid interface to its top and the maximum velocity up to about $46 \mu \mathrm{m} / \mathrm{s}$ appears at the top. This bottom-to-top flow pattern perfectly meets the request for bottom-to-top solute transport revealed by the in-situ observations. Furthermore, the Péclet number $P_{e} \approx 2.3$ (with $U=46 \mu \mathrm{m} / \mathrm{s}, L=200 \mu \mathrm{m}$ and $D=4 \times 10^{-9} \mathrm{~m}^{2} / \mathrm{s}$ ) bigger than unity demonstrates that these TEMHDF were sufficient to control the solute transport in the observed directional solidification of Al-4wt petCu alloy.

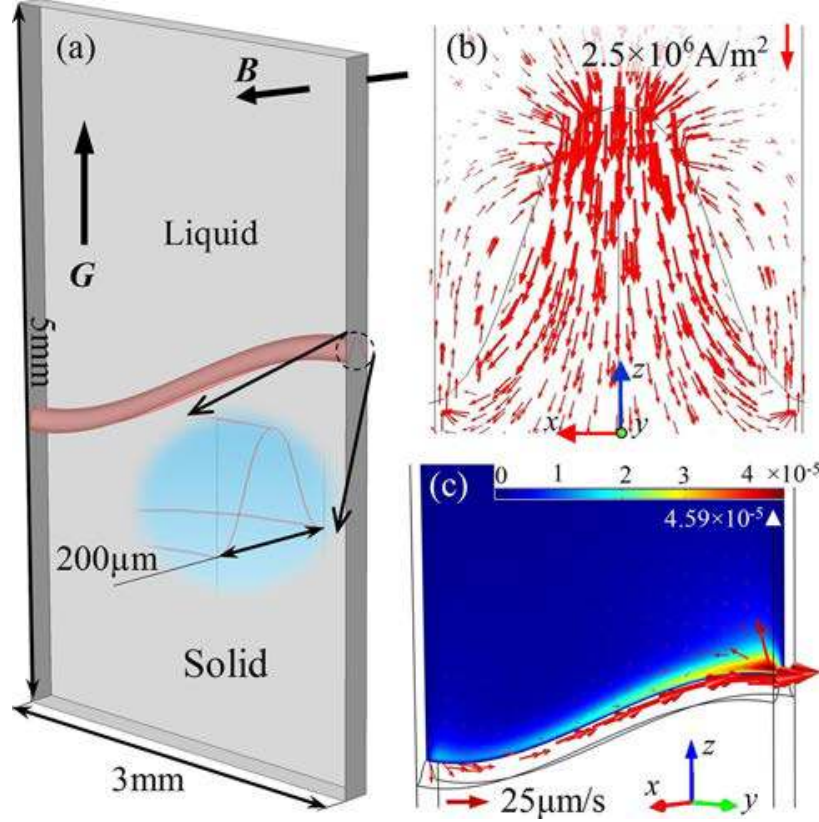

Fig. 7- (a) Geometry of the domain and its dimensions used by the simulation of TEMHDF in the observed directional solidification of $\mathrm{Al}-4 \mathrm{wt}$ petCu alloy under a $0.08 \mathrm{~T}$ transverse static magnetic field $(B)$, and the inserted picture shows that the solid-liquid interface used in this simulation is convex in $x$-axis direction $(G=3500 \mathrm{~K} / \mathrm{m}$ $\left.\left(3500{ }^{\circ} \mathrm{C} / \mathrm{m}\right)\right)$; (b) Computed TEC distribution near to solid-liquid interface is shown by the red arrows in an $x-z$ plane; $(c)$ Computed flow field of TEMHDF shown by the red arrows and the colored $y-z$ plane indicates their magnitudes (the unit in caption is $\mathrm{m} / \mathrm{s}$ ).

\section{SIMULATIONS OF TEMHDF UNDER AN AXIAL STATIC MAGNETIC FIELD}

Considering $\vec{F}=\vec{j} \times \vec{B}$, it is known that both directions of TEC and the magnetic field determine Lorentz forces' direction and thus decide the flow field of TEMHDF in the magnetic field-assisted solidification. Therefore, knowing how TEMHDF behave under an axial static magnetic field is worthy and indispensable for gaining a comprehensive understanding on the influence of static magnetic field on solidification of metals. To do this, the corresponding 3D simulations were carried out using the numerical model that has been verified by both ex-situ experiments and in-situ observations. By coupling the heat transfer, electric current and fluid flow modules and using relevant parameters in Table I TEMHDF under a $0.5 \mathrm{~T}$ axial static magnetic field were computed with the same geometry as shown in Figure 3(a). The computed flow field is presented by red arrows in Figure 8(a). It indicates that TEMHDF under axial magnetic field flow in a vortices pattern which is much clearer by seeing it from the top as shown in Figure 8(b). The colored $x-z$ plane in Figure 8(a) suggests that the maximum velocities of these TEMHDF appear near to the solid-liquid interface's top. This is reasonable because the highest TEC densities are in the same region as demonstrated by the simulation shown in Figure 3(b) and 3(c). These higher density TEC interacting with a constant static magnetic field leads to stronger Lorentz forces and thus 


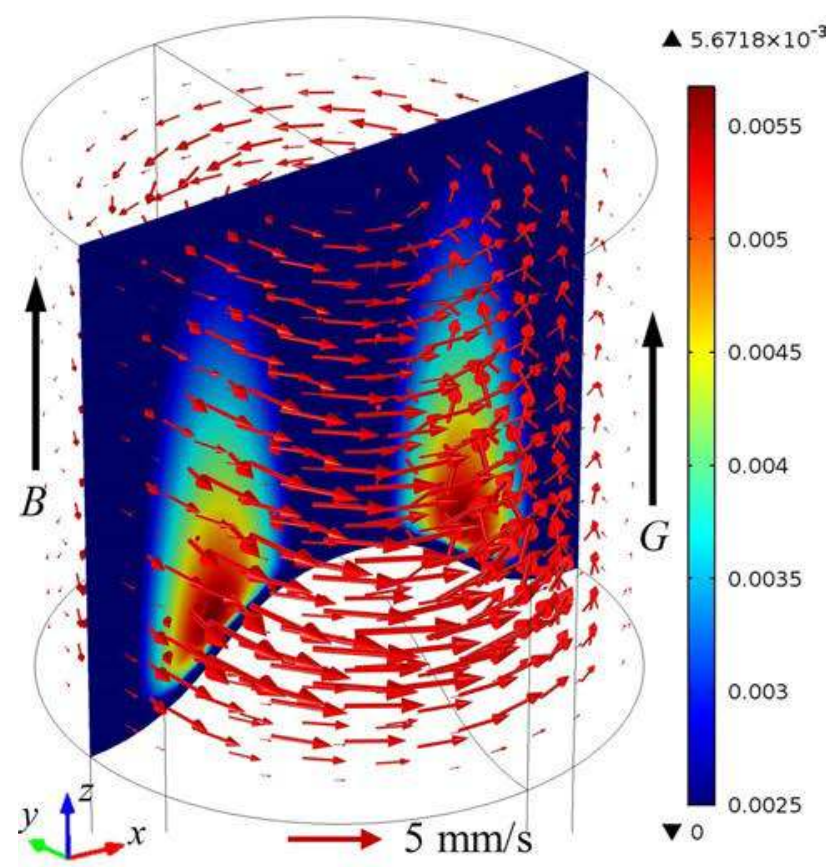

(a)

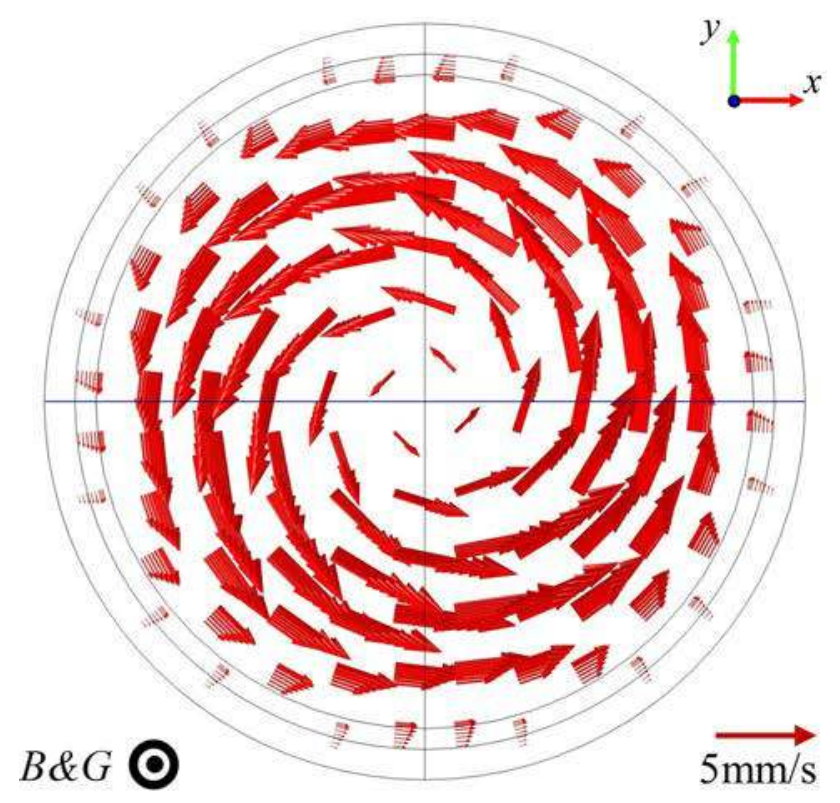

(b)

Fig. 8- (a) The red arrows show the computed flow field of TEMHDF under a $0.5 \mathrm{~T}$ axial static magnetic field $(B)$ with the geometry shown in Figure 3(a), and the colored $x-z$ plane indicates their magnitudes (the unit in caption is $\mathrm{m} / \mathrm{s}, \quad G=6000 \mathrm{~K} / \mathrm{m}$ $\left.\left(6000^{\circ} \mathrm{C} / \mathrm{m}\right)\right) ;(b)$ Top view of the computed flow flied of TEMHDF.

produces faster TEMHDF. With such roundabout flowing TEMHDF in the melt the denser $\mathrm{Cu}$-enriched melts could concentrate at the periphery of the solid-liquid interface. Two phenomena may contribute to this periphery segregation. One is the solute transport caused by the Taylor convection ${ }^{[39]}$ that a secondary convection triggered by vortices flowing with an annular pattern in the vertical planes. In the other aspect, the denser
$\mathrm{Cu}$-enriched melts could be pushed outwards from the center due to centrifugal effect of the roundabout flowing TEMHDF. ${ }^{[40]}$ The periphery segregation of $\mathrm{Cu}$ could suppress the local growth and may lead to the increase of originally convex interface's gibbous degree. This is well consistent with our previous findings from the experiments of directional solidification of $\mathrm{Al}-\mathrm{Cu}$ alloys under various axial static magnetic fields. ${ }^{[30]}$

\section{CONCLUSIONS}

A physical model was proposed to interpret thermoelectric currents (TEC) at the solid-liquid interface in directional solidification of metallic alloys. This model was further confirmed by the 3D simulation of TEC for a given convex solid-liquid interface. It revealed that TEC exist during solidification of alloys naturally, flow through both liquid and solid phases, and close their loop via crossing the interface. In the magnetic field-assisted solidification thermoelectric magnetohydrodynamic flows (TEMHDF) can be produced by the interaction between TEC and the applied magnetic field. TEMHDF and their influences on the solid-liquid interface shape in a transverse static magnetic field-assisted directional solidification were systematically investigated through ex-situ experiments, in-situ observations, and their corresponding simulations. The experiments and simulations are well consistent with each other, and this confirms both the existence of TEMHDF and their impacts on the solid-liquid interface shape. TEMHDF under an axial static magnetic field were computed, and their roundabout flow pattern was uncovered. The gibbous degree of the originally convex interface was predicted to increase due to the periphery segregation caused by centrifugal effect of the roundabout flowing TEMHDF and their resultant Taylor/secondary convections. This well agrees with the published experimental results. Therefore, we can argue that TEMHDF are capable to affect the shape of solid-liquid interface, especially its curvature, during directional solidification and may be controlled by adjusting the intensity or direction of magnetic field. This provides a novel/ potential approach to tailor the solidified structure from its originating, the solid-liquid interface, by applying a static magnetic field to solidification.

\section{ACKNOWLEDGMENTS}

This study is partly supported by the Shanghai Committee of Science and Technology (Nos. 13521101102, 13DZ1108200, and 13521101102), the program of Youth Eastern Scholar (QD2015035), and the CNRS/ANR OPTIMAG Project in France. We are grateful to T. Lafford and X. Guichard in European Synchrotron Radiation Facility (ESRF, Grenoble) for their help on experiments, and the first author appreciates the support from program of Marie-Curie IPACTS (No. 268696). 


\section{REFERENCES}

1. M. Garnier: ISIJ Int., 1990, vol. 30, pp. 1-7.

2. Y. Mitsui, K. Oikawa, K. Koyama, and K. Watanabe: J. Alloys Compd., 2013, vol. 577, pp. 315-19.

3. X. Li, Y. Fautrelle, and Z.M. Ren: Scripta Mater., 2008, vol. 59, pp. $407-10$.

4. S. Asai: ISIJ Int., 2007, vol. 47, pp. 519-22.

5. L. Li, Z.H. Zhao, Y.B. Zuo, Q.F. Zhu, and J.Z. Cui: J. Mater. Res., 2013, vol. 28, pp. 1567-73.

6. Z. Sun, X. Zhang, M. Guo, L. Pandelaers, J. Vleugels, O. Van der Biest, K. Van Reusel, and B. Blanpain: J. Colloid Interface Sci., 2012, vol. 375, pp. 203-12.

7. Q. Wang, T. Liu, A. Gao, C. Zhang, C.J. Wang, and J.C. He: Scripta Mater., 2007, vol. 56, pp. 1087-90.

8. S Chandrasekhar: Philos. Mag. Ser., 1954, vol. 7 (45), pp. 1177-91.

9. D. Samanta and N. Zabaras: Int. J. Heat Mass Transf., 2006, vol. 49, pp. 4850-66.

10. N. Dropka, C. Frank-Rotsch, and P. Rudolph: J. Cryst. Growth, 2013, vol. 365 , pp. 64-72.

11. H. A. Chedzey and D.T.J. Hurle: Nature, 1966, vol. 5039, pp. 933-34.

12. H. P. Utech and M.C. Flemings: J. Appl. Phys., 1966, vol. 37, pp. 2021-24.

13. A.E. Mikelson and Y.K. Karklin: J. Cryst. Growth, 1981, vol. 52 , pp. $524-29$.

14. T. Alboussiere, R. Moreau, and D. Camel: C. R. Acad. Sci. Paris, 1991, vol. 313, pp. 749-55.

15. W. Murgatroyd: Improvements in or relating to heat transfer systems, UK patent, appl. 20911/51.,1951.

16. M.A. Jaworski, T.K. Gray, M. Antonelli, J.J. Kim, C.Y. Lau, M.B. Lee, M.J. Neumann, W. Xu, and D.N. Ruzic: Phys. Rev. Lett., 2010, vol. 104, p. 094503.

17. J.A. Shercliff: J. Fluid Mech., 1979, vol. 91, pp. 231-51.

18. P. Lehmann, R. Moreau, D. Camel, and R. Bolcato: Acta Mater., 1998, vol. 46, pp. 4067-79.

19. O. Lielausis, J. Kjavins, A. Mikelsons, J. Valdmanis, and V. Golovanov: Proceedings of International Symposium on Electromagnetic Processing of Materials, Nagoya Japan ISIJ, 1994, pp. 555-60.

20. Q. Liu: Master Thesis, 2002, Liaoning Technical University, China,

21. H. Yasuda, K. Nogita, C. Gourlay, M. Yoshiya, and T. Nagira: $J$. Japan Weld. Soc., 2009, vol. 78, pp. 6-9.
22. A. Kao: Doctoral Thesis, 2010, University of Greenwich, United Kingdom.

23. X. Li, Y. Fautrelle, and Z.M. Ren: Acta Mater., 2007, vol. 55, pp. 1377-86.

24. X. Li, Y. Fautrelle, and Z.M. Ren: Acta Mater., 2008, vol. 56, pp. 3146-61.

25. X. Li, Y. Fautrelle, Z.M. Ren, A. Gagnoud, R. Moreau, Y.D. Zhang, and C. Esling: Acta Mater., 2009, vol. 57, pp. 1689-1701.

26. X. Li, Z.M. Ren, A. Gagnoud, O. Budebkova, and Y. Fautrelle: Metall. Mater. Trans. A, 2011, vol. 42A, pp. 3459-71.

27. X. Li, A. Noeppel, B. Saadi, O. Budebkova, K. Zaidat, A. Ciobanas, Z.M. Ren, and Y. Fautrelle: Trans. IIM, 2009, vol. 62, pp. 465-67.

28. J. Wang, Y. Fautrelle, Z.M. Ren, H. Nguyen-Thi, G. Salloum-Abou-Jaoude, G. Reinhart, N. Mangelinck-Noel, X. Li, and I. Kaldre: Appl. Phys. Lett., 2014, vol. 104, p. 121916.

29. C.W. Lan, I.F. Lee, and B.C. Yeh: J. Cryst. Growth, 2003, vol. 254 , pp. $503-15$.

30. X. Li, A. Gagnoud, Z.M. Ren, Y. Fautrelle, and R. Moreau: Acta Mater., 2009, vol. 57, pp. 2180-97.

31. I. Kaldre, Y. Fautrelle, J. Etay, A. Bojarevics, and L. Buligins: Magnetohydrodynamics, 2010, vol. 46, pp. 371-80.

32. J.D. Verhoeven and E.D. Gibson: J. Cryst. Growth, 1969, vol. 5, pp. 235-38.

33. G.H. Rodway and J.D. Hunt: J. Cryst. Growth, 1991, vol. 112, pp. 563-70.

34. F. Baltaretu, J. Wang, S. Letout, Z.M. Ren, X. Li, O. Budenkova, and Y. Fautrelle: Magnetohydrodynamics, 2015, vol. 51, pp. 3-13.

35. R.J. Schaefer and S.R. Coriell: Metall. Trans. A, 1984, vol. 15A, pp. 2109-15.

36. W.W. Mullins and R.F. Sekerka: J. Appl. Phys., 1964, vol. 35, pp. $444-51$.

37. A. Bogno, H. Nguyen-Thi, A. Buffet, G. Reinhart, B. Billia, N. Mangelinck-Noël, N. Bergeon, J. Baruchel, and T. Schenk: Acta Mater., 2011, vol. 59, pp. 4356-65.

38. A. Bognoa, G. Reinharta, A. Buffetc, H. Nguyen-Thi, B. Billiaa, T. Schenkc, N. Mangelinck-Noëla, N. Bergeona, and J. Baruchel: J. Cryst. Growth, 2011, vol. 318, pp. 1134-38.

39. G.I. Taylor: Philos. Trans. R. Soc. Lond. Ser. A, 1923, vol. 223, pp. 289-343.

40. Y. Watanabe and S. Oike: Acta Mater., 2005, vol. 53, pp. 163141. 